\title{
Recyclable Crosslinked O-Carboxymethyl Chitosan for Removal of Cationic Dye from Aqueous Solutions
}

\author{
Kishor Sarkar, Manish Debnath and P.P. Kundu*
}

Department of Polymer Science \& Technology, University of Calcutta, India

\begin{abstract}
Carboxymethyl chitosan have been investigated for many biomedical applications as well as for the removal of metal ion and cationic dye from aqueous solution. But, carboxymethyl chitosan is soluble in water and therefore, it is difficult to reuse. The aim of the work was to prepare cross-linked O-carboxymethyl chitosan (OCMCTS) with different degree of substitution for the removal of Crystal Violet (CV) cationic dye from aqueous solution. The influence of the parameters such as initial $\mathrm{pH}$ of the dye solution, initial dye concentration, adsorption temperature, degree of substitution of OCMCTS and adsorption time on the adsorption capacity was studied using batch method. The results showed that the adsorption capacity of modified CTS increased from $28.49 \mathrm{mg} / \mathrm{g}$ to $239.54 \mathrm{mg} / \mathrm{g}$. The kinetic study of OCMCTS showed that it follows the pseudo-second-order kinetic rather than pseudo-first-order kinetic. The adsorption equilibrium showed that the experimental data could be best fitted to the Langmuir equation. The desorbed OCMCTS can be reused to absorb the cationic dyes. Therefore, cross-linked OCMCTS may be favorable adsorbent and could be employed as low-cost alternatives for the removal of cationic dyes in wastewater treatment.
\end{abstract}

Keywords: O-Carboxymethyl chitosan; Cross-linked; Crystal violet; Isotherms; Desorption

\section{Introduction}

Water is a basic necessity for the entire living organism in this world. When, water gets contaminated due to presence of various pollutants in it, it becomes dangerous for the living beings and causes several diseases and harmful effects by consumption in different ways. Therefore, availability of pure water for drinking is fast becoming a scarce resource due to wide spread pollution. Among the different pollutants of aquatic ecosystems, dyes are the largest and most important industrial chemicals for which world production in 1978 was estimated at 640,000 tons [1]. Substantial volume of water is consumed daily by many industries such as textile, rubber, cosmetics, paper, plastics as well as dyestuffs and they also use chemicals during manufacturing and dyes to color their products. As a result, they generate a considerable amount of polluted wastewater [2-5]. Due to their possible toxicity, carcinogenicity and resistant to environmental conditions like light, effects of $\mathrm{pH}$ and microbial attack [6], it is desirable to remove coloring material from wastewater. Colored dyes can be removed from wastewater by several methods including coagulation and flocculation [7], membrane separation [8], oxidation [9], electro-coagulation [10], and adsorption on activated carbon and clays [11]. Adsorption process is the most widely used technique for decontamination of dyecontaining effluents. Currently, activated carbon is the most widely used commercial adsorbent due to its excellent adsorption capacity [12]. But, high cost and regeneration are the main drawbacks for the use of activated carbon as adsorbent [13]. To overcome this problem, most researchers have focused on the development of low cost and effective new adsorbents [14]. In recent years, many works on low-cost adsorbents have been studied for dye removal such as cotton, fly ash, guava leaf powder, sugarcane bagasse pith, rice husk, coconut coir and chitosan [15-21].

Recently, most researchers have concentrated towards natural polymeric materials, because they are renewable, biodegradable, non-toxic and an environment friendly material [22]. Among the natural polymeric materials, chitosan is the most attractive polymer due to its low cost and ready availability. Chitosan (CTS) is a linear copolymer composed of (1-4)-linked D-glucosamine and N-acetyl-D- glucosamine and it is obtained by alkaline hydrolysis of chitin (second abundant polymer in nature after cellulose) [23]. Chitin is obtained from crustaceans (crab, krill, crayfish) primarily because a large amount of the crustacean's exoskeleton is available as a by-product of food processing. CTS is widely used for the removal of heavy, transition metals and dyes as a well-known sorbent [24-26]. Because of its cationic nature, CTS adsorbs the anionic dyes and in very small amount of the cationic dyes. Recently, researchers showed interest in chemical modification of CTS to enhance their properties and consequently their potential applications $[27,28]$. Carboxymethylation of chitosan is very attractive method among the various chemical modifications, because it introduces active carboxyl $(-\mathrm{COOH})$ groups into the molecule. This leads to an increase in the adsorption capacity of chitosan for heavy, transition metals and dyes [29,30]. But, carboxymethyl chitosan cannot regenerate after adsorption because it is soluble in water, which is the main drawback of carboxymethyl chitosan to use an effective adsorbent for dye waste water treatment. To overcome this problem of carboxymethyl chitosan, here we prepared cross-linked O-carboxymethyl chitosan for cationic dye, crystal violet $(\mathrm{CV})$ as a model cationic dye separation from aqueous solution. No one reported the cationic dye adsorption by cross-linked O-carboxymethyl chitosan (OCMCTS) till date. Therefore, the aim of this study was to investigate the adsorption of CV onto cross-linked OCMCTS in detail. The effects of initial $\mathrm{pH}$ of the dye solution, dye concentration, adsorption temperature and degree of substitution of OCMCTS were investigated. The adsorption kinetics and isotherms for CV dye onto OCMCTS and the desorption study were also carried out.

${ }^{*}$ Corresponding author: P.P. Kundu, Department of Polymer Science \& Technology, University of Calcutta, 92 A. P. C. Road, Kolkata-9, India, Tel: \& Fax: +91 033 2352-5106; E-mail: ppk922@yahoo.com

Received June 13, 2012; Accepted July 23, 2012; Published July 26, 2012

Citation: Sarkar K, Debnath M, Kundu PP (2012) Recyclable Crosslinked O-Carboxymethyl Chitosan for Removal of Cationic Dye from Aqueous Solutions. Hydrol Current Res 3:138. doi:10.4172/2157-7587.1000138

Copyright: $\odot 2012$ Sarkar K, et al. This is an open-access article distributed under the terms of the Creative Commons Attribution License, which permits unrestricted use, distribution, and reproduction in any medium, provided the original author and source are credited. 


\section{Experimental}

\section{Materials}

Chitosan was obtained from Acros Organics (USA). The degree of deacetylation and weight average molecular weight (determined by Gel Permeation Chromatography, Waters, USA) are 86\% and 222 $\mathrm{kDa}$, respectively. Monochloroacetic acid was purchased from Loba Chemie (India) and glutaraldehyde (GA) was obtained from Merck, India. Other reagents used were all analytical grade and used without further purification.

\section{Crystal violet stock solution}

Crystal violet, also known as hexamethyl pararosaniline chloride, $\lambda_{\max }=590 \mathrm{~nm}$ is a basic dye and it was purchased from RFCL Limited, India. The molecular formula and molecular mass of $\mathrm{CV}$ are $\mathrm{C}_{25} \mathrm{H}_{30} \mathrm{ClN}_{3}$ and 407.98, respectively. The chemical structure of $\mathrm{CV}$ is shown in Figure 1. Crystal violet stock solution of $2000 \mathrm{mg} / \mathrm{L}$ was prepared by dissolving $2 \mathrm{~g}$ of the dye into $1000 \mathrm{ml}$ double distilled water. The $\mathrm{pH}$ of the dye solution was adjusted by dilute $\mathrm{HCl}$ or $\mathrm{NaOH}$. The stock solution was used throughout the whole experiment by fresh dilution.

\section{Preparation of crosslinked O-Carboxymethyl chitosan}

O-carboxymethyl chitosan was prepared according to the previous report [31] with slight modification. Briefly, $2 \mathrm{~g}$ of CTS was swelled in $40 \mathrm{ml}$ isopropanol and water mixture $(8: 2 \mathrm{v} / \mathrm{v}$ ratio) containing 6 g sodium hydroxide at a temperature of $50^{\circ} \mathrm{C}$ for $1 \mathrm{hr}$. Then, different amounts of monochloroacetic acid dissolved in isopropanol was added drop wise into the reaction mixture over the period of $30 \mathrm{~min}$ to prepare carboxymethyl chitosan with different degree of substitution (DS). The reaction was continued with constant stirring for another 4 $\mathrm{hr}$ at the same temperature. Finally, the reaction was stopped by adding $70 \%$ ethyl alcohol. Then, the product was filtered and washed with $80 \%$ ethyl alcohol to remove salt and water. The OCMCTS was dried under vacuum overnight.

To prepare cross-linked OCMCTS, carboxymethyl chitosan was dissolved in distilled water and then, the OCMCTS solution was added drop wise into $1 \%(\mathrm{v} / \mathrm{v})$ glutaraldehyde solution with constant stirring at high speed. The mixture was kept at $50^{\circ} \mathrm{C}$ for $30 \mathrm{~min}$ for complete cross-linking. The cross-linked OCMCTS was collected by centrifugation at $5000 \mathrm{rpm}$. and washed with water for few times to remove unreacted glutaraldehyde. Finally, the product was vacuum dried for $24 \mathrm{hr}$ at $50^{\circ} \mathrm{C}$.

\section{Determination of degree of substitution}

The degree of substitution (DS) of OCMCTS was determined by potentiometric titration [32]. $0.2 \mathrm{~g}$ OCMCTS was dissolved in $40 \mathrm{~mL}$<smiles>CN(C)c1cccc(C(=C2C=CC(=[N+](C)C)C=C2)c2cccc(N(C)C)c2)c1</smiles>

Figure 1: Chemical structure of crystal violet. distilled water and the $\mathrm{pH}$ of the solution was adjusted to $\mathrm{pH}<2$ by adding hydrochloric acid. Then, the OCMCTS solution was titrated with $0.1 \mathrm{M}$ aqueous $\mathrm{NaOH}$ and the corresponding $\mathrm{pH}$ values of the solution was simultaneously recorded by a laboratory $\mathrm{pH}$ meter (MakeCD, Model: APX175 E/C, India). The volume of aqueous $\mathrm{NaOH}$ was determined by the second order differential method. The degree of substitution (DS) can be calculated as follows:

$$
\begin{aligned}
& D S=\frac{161 \times A}{m_{C M C T S}-58 \times A} \\
& A=V_{\mathrm{NaOH}} \times C_{\mathrm{NaOH}}
\end{aligned}
$$

Where, $V_{\mathrm{NaOH}}$ and $C_{\mathrm{NaOH}}$ are the volume and concentration of aqueous $\mathrm{NaOH}$, respectively, $m_{\text {CMCTS }}$ is the mass of OCMCTS (g), 161 and 58 are the respective molecular weights of glucosamine (repeating unit of chitosan) and carboxymethyl group.

\section{Characterization of OCMCTS}

OCMCTS was characterized by infrared (FT-IR) spectrophotometer. The infrared spectra were recorded at the frequency range of $4000-500 \mathrm{~cm}^{-1}$ with 42 consecutive scans at a $4 \mathrm{~cm}^{-1}$ resolution on a Bruker Alpha ATR FT-IR spectrometer.

X-ray diffraction spectrometry of chitosan, OCMCTS and crosslinked OCMCTS in the powder form were performed by a wide angle $\mathrm{X}$-ray scattering diffractometer (Panalytical X-Ray Diffractometer, model- X'pert Pro) with $\mathrm{Cu} \mathrm{K}$ radiation $(\lambda=1.5444)$ in the range $5-35^{\circ}$ (20) at $40 \mathrm{kV}$ and $30 \mathrm{~mA}$.

\section{Adsorption Studies of CV by Batch Technique}

Adsorption kinetics and isotherms were carried out by batch technique. All the batch experiments were carried out on a water bath and stirring with a magnetic stirrer at a speed of $120 \mathrm{rpm}$. In each experiment, a fixed mass of OCMCTS $(50 \mathrm{mg}$ ) was added into 25 $\mathrm{ml}$ of an aqueous solution of $\mathrm{CV}$ at a known concentration in a 250 $\mathrm{ml}$ conical flask. The influence of $\mathrm{pH}$ on $\mathrm{CV}$ removal was studied by adjusting CV solutions $(800 \mathrm{mg} / \mathrm{L})$ to different $\mathrm{pH}$ values $(2.0,4.0,6.0$, 8.0 and 10.0) using $\mathrm{pH}$ meter at $30^{\circ} \mathrm{C}$ for $4 \mathrm{hr}$. The effects of initial dye concentrations on the adsorption were carried out at $30^{\circ} \mathrm{C}(\mathrm{pH}$ 8.0) for $4 \mathrm{hr}$. The effect of temperature on dye adsorption was carried out at different temperatures $\left(30^{\circ} \mathrm{C}, 40{ }^{\circ} \mathrm{C}, 50^{\circ} \mathrm{C}\right.$ and $\left.60{ }^{\circ} \mathrm{C}\right)$ in 25 $\mathrm{mL}$ of dye solution $(800 \mathrm{mg} / \mathrm{L}, \mathrm{pH} 8.0)$ with $0.05 \mathrm{~g}$ of OCMCTS for $4 \mathrm{hr}$. For kinetic study, $800 \mathrm{mg} / \mathrm{L}$ dye solutions ( $25 \mathrm{~mL}, \mathrm{pH}$ 8.0) were agitated with $50 \mathrm{mg}$ of adsorbent at $30^{\circ} \mathrm{C}$ for $4 \mathrm{hr}$. Batch equilibrium adsorption experiments were carried out by agitating $25 \mathrm{~mL}$ of various dye concentrations of $\mathrm{CV}$ solution at $\mathrm{pH} 8.0$ with $50 \mathrm{mg}$ of adsorbent at $30 \mathrm{oC}$ until equilibrium was established.

For kinetic study, the samples were withdrawn from the flask at predetermined time intervals. The absorbencies of the samples were measured using a UV-vis spectrophotometer (LAMBDA 25, PerkinElmer) at $590 \mathrm{~nm}$ corresponding to a maximum absorbency of CV. The amount of adsorption, $\mathrm{q}(\mathrm{mg} / \mathrm{g})$ was calculated by the following equation

$$
q=\frac{\left(C_{0}-C_{t}\right) V}{W}
$$

where $C_{0}$ and $C_{t}(\mathrm{mg} / \mathrm{L})$ are the concentrations of dye at initial and at time $t$, respectively. $V$ is the volume of solution (L) and $\mathrm{W}$ is the mass of dry adsorbent used (g). 


\section{Desorption study}

For the desorption studies, $50 \mathrm{mg}$ of OCMCTS was loaded with CV using $25 \mathrm{~mL}$ of $800 \mathrm{mg} / \mathrm{L} \mathrm{CV}$ solution at $\mathrm{pH}$ 8.0. Agitation period was $180 \mathrm{~min}$ and agitation rate was fixed at $200 \mathrm{rpm}$. CV loaded OCMCTS was collected by centrifugation and gently washed with distilled water to remove any unadsorbed CV. The amount of CV adsorbed per gram of OCMCTS was determined by using the supernatant of CV solution. The loaded OCMCTS was agitated with $25 \mathrm{~mL} 0.2 \mathrm{M} \mathrm{HCl}$ solution ( $\mathrm{pH}$ 2.0) at $30^{\circ} \mathrm{C}$ for $2 \mathrm{hr}$ and the sample was collected at different time intervals for determination of the eluted dye concentration to calculate the percentage of desorption.

\section{Results and Discussion}

\section{FT- IR Spectra of OCMCTS}

The synthetic route of OCMCTS and cross-linked OCMCTS is shown in Figure 2. The FT-IR spectrums of chitosan and OCMCTS are shown in Figure 3. Figure 3a shows the basic characteristic peaks of CTS at: $3427.73 \mathrm{~cm}^{-1}$ (O-H stretch and N-H stretch, overlap), 2922.49 and $2859.82 \mathrm{~cm}^{-1}$ (C-H stretch), $1652.90 \mathrm{~cm}^{-1}$ (NH-CO (I) stretch), 1597.66 $\mathrm{cm}^{-1}$ (N-H bend), $1154.09 \mathrm{~cm}^{-1}$ (bridge-O- stretch) and $1092.74 \mathrm{~cm}^{-1}$ (C-O stretch) [33]. The $\mathrm{H}$ form of OCMCTS shows the strong peaks at $1711.57 \mathrm{~cm}^{-1}(-\mathrm{COOH}), 1604.96$ and $1543.66 \mathrm{~cm}^{-1}\left(-\mathrm{NH}_{3}^{+}\right)$, which are the characteristic peaks of $\mathrm{O}$-carboxymethyl chitosan (Figure $3 \mathrm{~b}$ ) [34]. Figure 3c shows the IR spectrum of Na salt of OCMCTS. The characteristic peak at $1601.15 \mathrm{~cm}^{-1}$ is due to the asymmetric stretching vibrations of $-\mathrm{COO}^{-}$Carboxylate ions and $\mathrm{N}-\mathrm{H}$ bending vibrations and the symmetric stretching vibration of $-\mathrm{COO}^{-}$
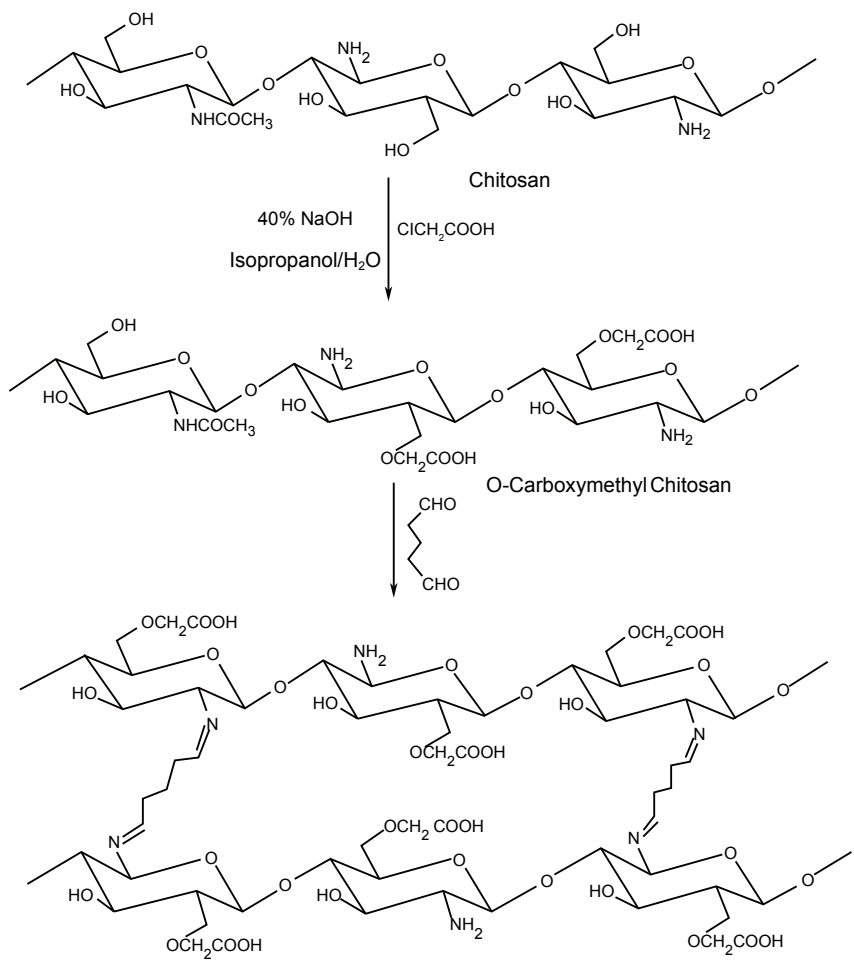

Crosslinked O-Carboxymethyl Chitosan

Figure 2: Synthetic route for synthesis of cross-linked o-carboxymethyl chitosan. with GA, a superimposed band for asymmetric stretching vibration of carboxylate ion and $C=N$ bond is appeared at $1643.81 \mathrm{~cm}^{-1}$ and the peak intensity for $-\mathrm{CH}_{2}$ at $2928.64 \mathrm{~cm}^{-1}$ increases due to the introduction of GA (Figure 3d) [35]. The FTIR result confirms the cross-linking of OCMCTS by GA.

The X-ray diffraction of chitosan, OCMCTS and cross-linked OCMCTS is shown in Figure 4. Chitosan shows two different peaks at $2 \theta=10^{\circ}$ and $2 \theta=20^{\circ}$. The peak at $10^{\circ}$ was assigned to crystal form I and the strong peak at $20^{\circ}$ was assigned to form II (Figure 4a). But, for both OCMCTS (Figure 4b) and cross-linked OCMCTS (Figure $4 \mathrm{c}$ ), the peaks at $10^{\circ}$ was disappeared and the reflection at $20^{\circ}$ also significantly decreased. The reason may be attributed to the destruction of the intermolecular hydrogen bonds between the amine groups and hydroxyl groups of chitosan due to the graft copolymerization. These results indicate that the graft copolymerization caused destruction of the ordered crystal structure of the chitosan.

\section{Effect of pH on Adsorption}

During dye adsorption from aqueous solution, the $\mathrm{pH}$ of the aqueous solution is an important factor for dye separation, as it affects the surface charge of the adsorbent material as well as the degree of ionization of the dye molecule [36]. Therefore, the adsorption experiments are carried out at different $\mathrm{pH}$ values between 2 and 10 to evaluate the effect of the $\mathrm{pH}$ of the dye solution on the adsorption capacity of cross-linked OCMCTS. Figure 5 shows the effect of $\mathrm{pH}$ variations on the $\mathrm{CV}$ adsorption from the aqueous solutions, for initial $\mathrm{CV}$ concentration of $800 \mathrm{mg} / \mathrm{L}$ and $50 \mathrm{mg}$ of dry OCMCTS at $30^{\circ} \mathrm{C}$ for $4 \mathrm{~h}$. From Figure 5, the adsorption capacity of OCMCTS increases

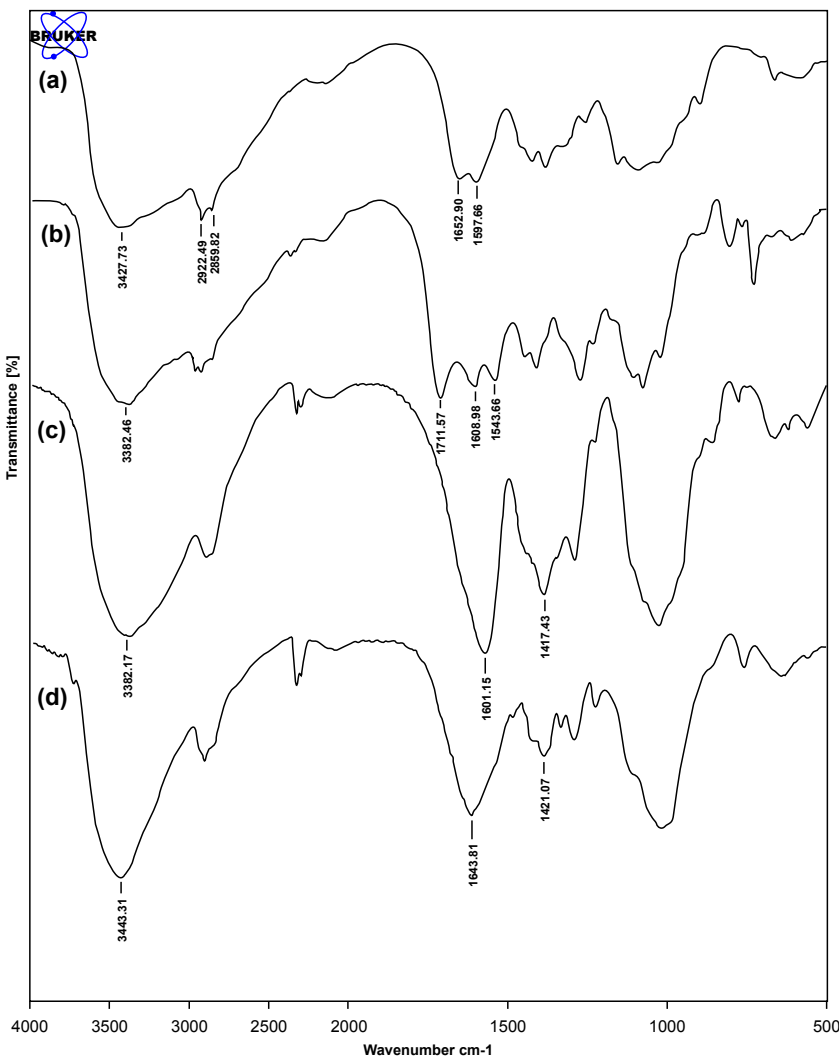

Figure 3: FT-IR spectrum of CTS (a), H form of OCMCTS (b), Na salt of OCMCTS (c) and cross-linked OCMCTS (d). 


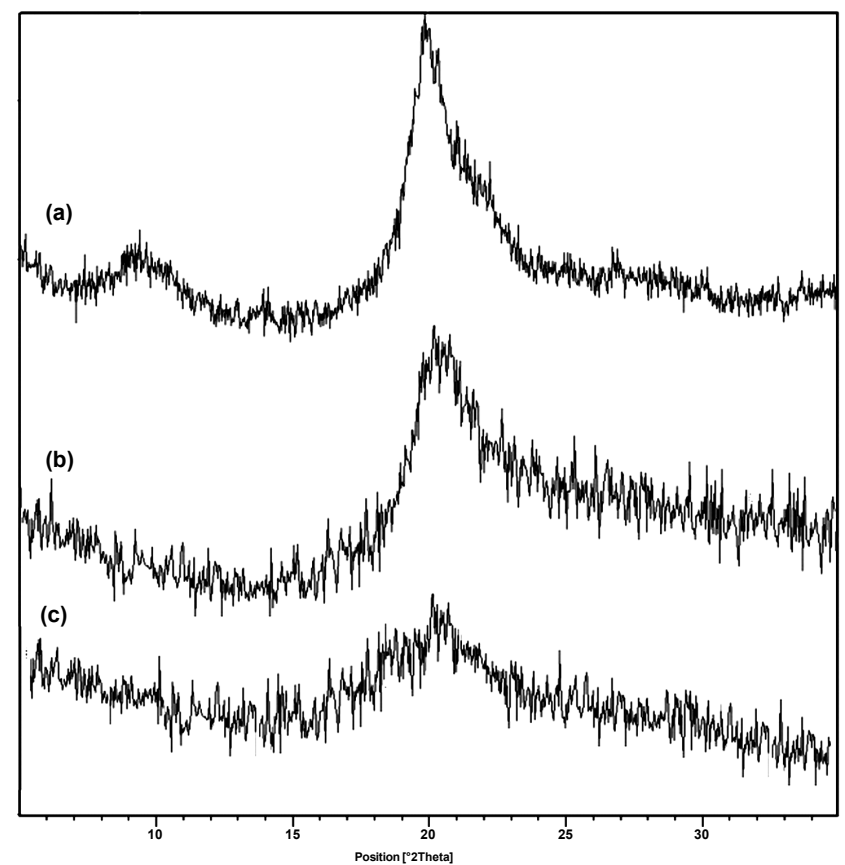

Figure 4: XRD of CTS (a), OCMCTS (b) and cross-linked OCMCTS (c).

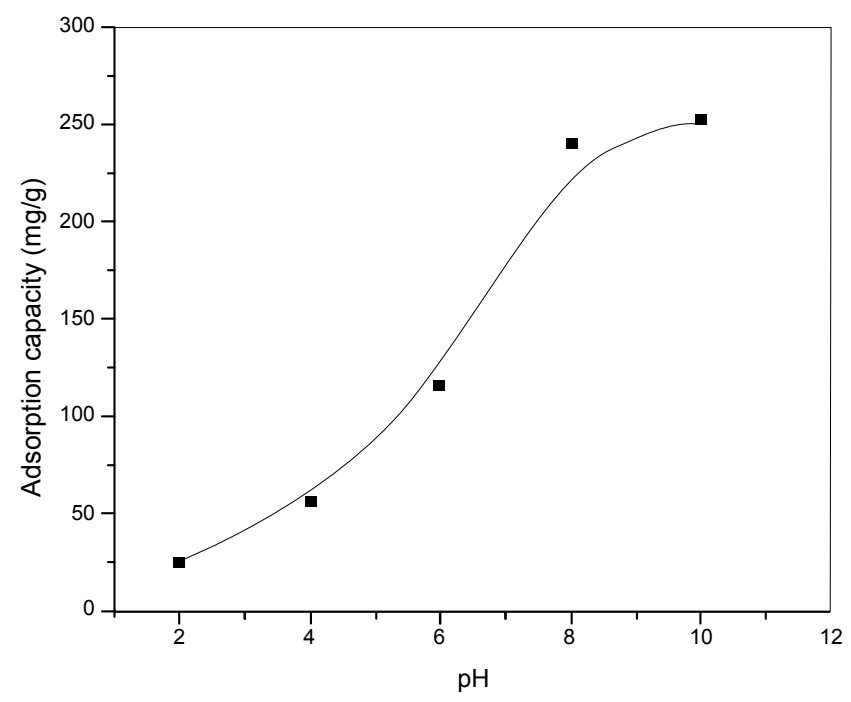

Figure 5: Effect of $\mathrm{pH}$ of the dye solution on adsorption capacity of OCMCTS for CV.

smoothly from $25.23 \mathrm{mg} / \mathrm{g}$ to $115.62 \mathrm{mg} / \mathrm{g}$, when the value of $\mathrm{pH}$ is increased from 2 to 4 . In the $\mathrm{pH}$ range from 6 to 8 , a sharp increase in the adsorption capacity (from $115.62 \mathrm{mg} / \mathrm{g}$ to $239.54 \mathrm{mg} / \mathrm{g}$ ) of OCMCTS is observed. A further increase in dye adsorption between $\mathrm{pH} 8.0$ and 10 is insignificant. Since, the optimum $\mathrm{pH}$ for dye adsorption by OCMCTS is found to be 8.0 because; the isoelectric point of OCMCTS with different DS was around 7.3 to 7.9 , determined by potentiometric titration (data not shown). This $\mathrm{pH}$ was used for further studies. As the $\mathrm{pH}$ increases, the charge density of the dye solution decreases, leading to the lowering of the electronic repulsion between the positively charged dye molecule and the surface of the adsorbent [37]. This results in an increase in the sorption of the dye. A little adsorption of the dye onto OCMCTS is observed at lower $\mathrm{pH}$ due to chemical interaction between CV dye and OCMCTS.

\section{Effect of temperature on adsorption}

The effect of temperature on adsorption capacity of cross-linked OCMCTS is investigated at different temperatures such as, 30, 40, 50 and $60^{\circ} \mathrm{C}$ at $\mathrm{pH}$ 8.0. From Figure 6, it is found that the adsorption capacity of CV on OCMCTS increased from $239.54 \mathrm{mg} / \mathrm{g}$ to 467.21 $\mathrm{mg} / \mathrm{g}$ with an increase of temperature from $30^{\circ} \mathrm{C}$ to $50^{\circ} \mathrm{C}$. This result suggests that the adsorption of $\mathrm{CV}$ on OCMCTS is endothermic in nature. The increase in adsorption capacity is due to the swelling of OCMCTS with increasing temperature, facilitating the penetration of dye molecules into the internal structure of OCMCTS [38]. This phenomenon also leads to an increment in the availability of active surface sites, increased porosity and in the total pore volume of the adsorbent. But, the adsorption capacity slightly decreased from 467.21 $\mathrm{mg} / \mathrm{g}$ to $445.26 \mathrm{mg} / \mathrm{g}$ with increasing the temperature from $50^{\circ} \mathrm{C}$ to $60^{\circ} \mathrm{C}$. This may be attributed by the fact that the mobility of the dye molecule increases with increasing the temperature, which may responsible for the decrease of adsorption capacity of cross-linked OCMCTS. The similar result was also obtained in our previous study [39].

\section{Effect of initial dye concentration on CV sorption}

The adsorption capacity of cross-linked OCMCTS for CV as a function of initial dye concentration is shown in Figure 7. Initial concentration of dye has an important role on the adsorption capacity. The initial concentrations of dye solution were varied within the range of $50-1000 \mathrm{mg} / \mathrm{L}$. It is observed that the adsorption capacity of OCMCTS sharply increased with an increase in the initial concentration of the dye solution and then reaches a plateau, indicating the saturation of the active sites of the adsorbents i.e. maximum adsorption of the adsorbents. As shown in Figure 5, the adsorption capacity of OCMCTS sharply increased from $10 \mathrm{mg} / \mathrm{g}$ to $230 \mathrm{mg} / \mathrm{g}$ with increasing dye concentration from $50 \mathrm{mg} / \mathrm{L}$ to $600 \mathrm{mg} / \mathrm{L}$ and remained almost constant with further increase in the dye concentration. The adsorption capacity of OCMCTS is observed to be much higher than

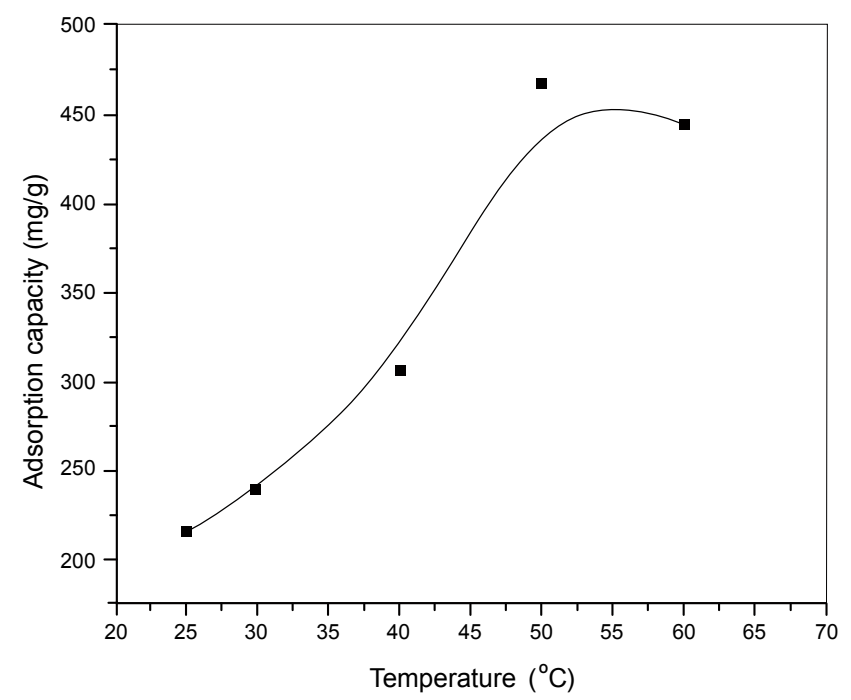

Figure 6: Effect of reaction temperature on adsorption capacity of OCMCTS for $\mathrm{CV}$. 


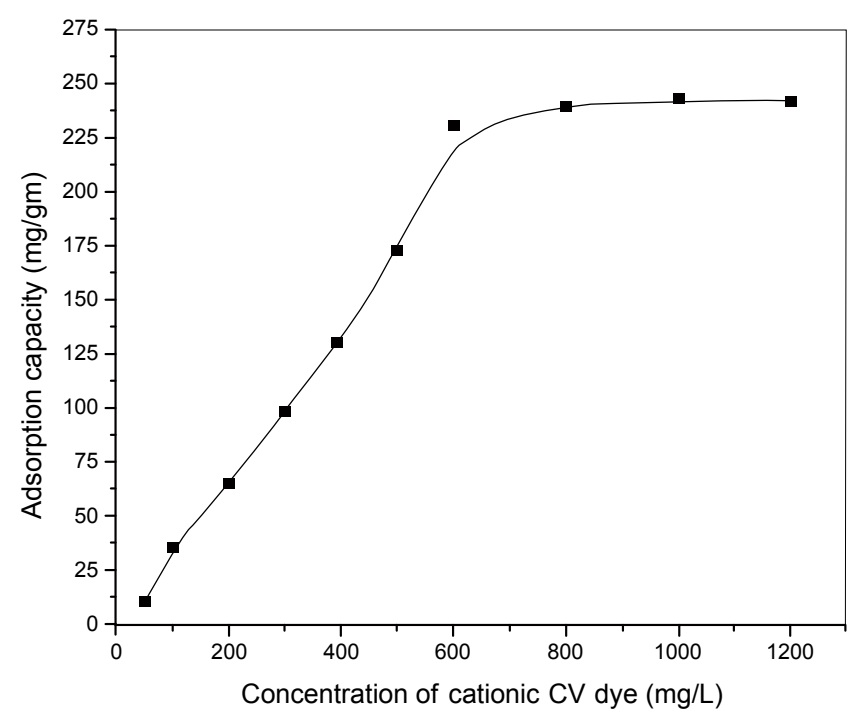

Figure 7: Effect of initial dye concentration on crystal violet adsorption by OCMCTS.

that for other materials previously reported as adsorbents for the removal of CV basic dye such as $65 \mathrm{mg} / \mathrm{g}$ by activated carbon obtained from rice husk [40] and $60 \mathrm{mg} / \mathrm{g}$ by activated carbon from male flowers of coconut tree [41].

\section{Effect of DS On CV adsorption}

The adsorption of CV dye onto cross-linked O-carboxymethyl chitosan with different degree of substitution is shown in Figure 8. It is found that the adsorption capacity of OCMCTS sharply increased with increasing the DS of OCMCTS from 0.28 to 0.64 and then it slightly decreased with further increasing the DS from 0.64 to 0.92 . This result may be explained by the fact that the number of anionic carboxyl group (-COO-) increased with increasing the degree of substitution of OCMCTS. As a result, the electrostatic interaction between the positively charged dye molecule and the negatively charged OCMCTS molecule also increased which results the enhancement of adsorption capacity of OCMCTS. On the other hand, the number of hydroxyl groups $(-\mathrm{OH})$ in repeating units of chitosan decreases with increasing the DS of OCMCTS, which may be resulted the slight decrease of adsorption capacity of OCMCTS.

\section{Adsorption kinetics}

Figure 9 shows the adsorption of CV onto cross-linked OCMCTS as a function of contact time. As observed in Figure 9, the adsorption of $\mathrm{CV}$ on OCMCTS occurs in two phases, firstly a rapid phase followed by a slow phase. The first phase involves a rapid adsorption of dye during the first $30 \mathrm{~min}$ followed by a slow phase of dye removal spread over a significantly longer period of time (>120 min) until the equilibrium is reached. According to the previous study [42], the rapid phase may last for several minutes to a few hours, while the slow stage continues for several hours to a day. The rapid phase probably occurs due to the availability of more active sites on the adsorbent. The active sites are gradually decreased by the occupancy of adsorbate and results in the slower phase.

To examine the kinetic mechanism of the adsorption process of $\mathrm{CV}$ on the cross-linked OCMCTS, the pseudo-first-order and the pseudosecond-order kinetics models are used to test the experimental data.

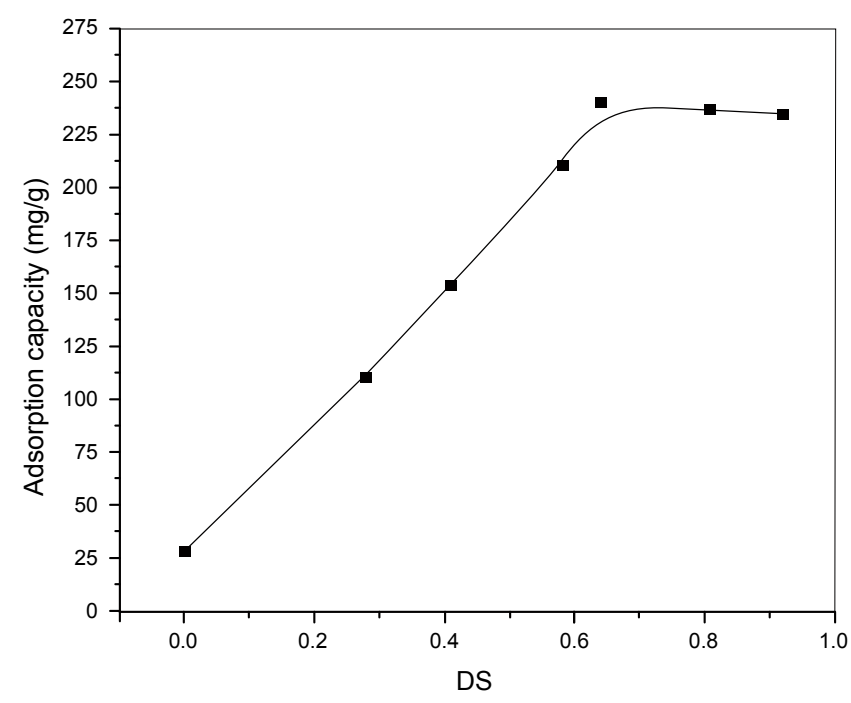

Figure 8: Effect of degree of substitution of OCMCTS on CV adsorption.

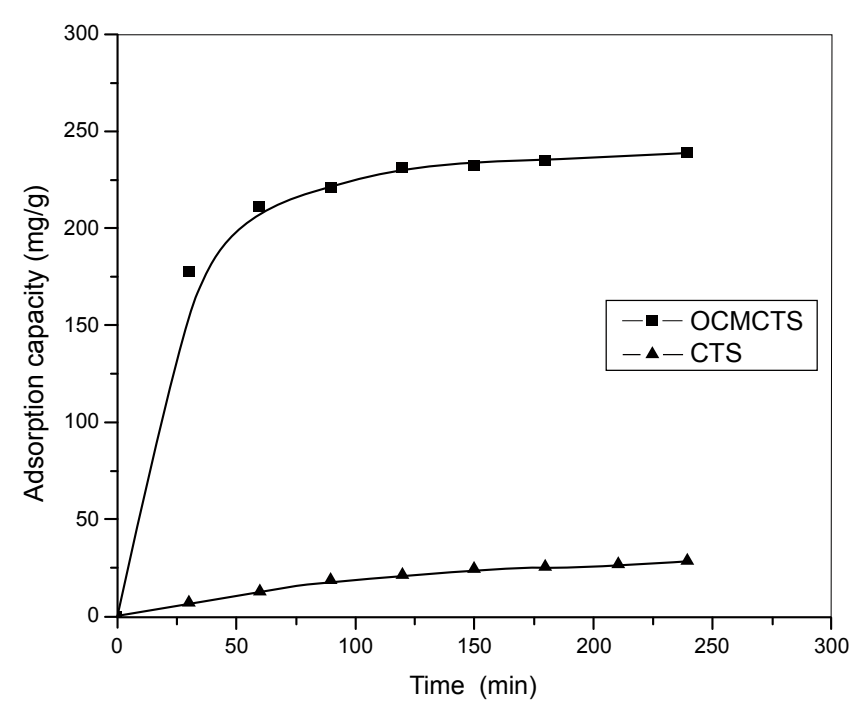

Figure 9: Adsorption of crystal violet by OCMCTS and CTS as a function of time.

The pseudo-first-order rate equation of Lagergren model [43] is as follows:

$$
\log \left(q_{e}-q_{t}\right)=\log q_{e}-\frac{k_{1} t}{2.303}
$$

The pseudo-second-order rate equation is given as below [44]:

$$
\frac{t}{q_{t}}=\frac{1}{k_{2} q_{e}^{2}}+\frac{t}{q_{e}}
$$

where $q_{e}$ and $q_{t}$ are the adsorption capacity $(\mathrm{mg} / \mathrm{g})$ at equilibrium and at time $t(\mathrm{~min})$, respectively. $k_{1}\left(\mathrm{~min}^{-1}\right)$ and $k_{2}\left(\mathrm{~g} \mathrm{mg}^{-1} \mathrm{~min}^{-1}\right)$ are the adsorption rate constants of pseudo-first-order and pseudo-secondorder adsorption rates, respectively. The linear plot of $\log \left(q_{e}-q_{t}\right)$ versus $t$ for pseudo-first-order model (Figure 10) and that of $(t / q t)$ versus $t$ for pseudo-second-order model (Figure 11) are drawn. The values of $q_{e}$ and the rate constants $k_{1}$ and $k_{2}$ can be obtained from the plot of experimental data. 
Citation: Sarkar K, Debnath M, Kundu PP (2012) Recyclable Crosslinked O-Carboxymethyl Chitosan for Removal of Cationic Dye from Aqueous Solutions. Hydrol Current Res 3:138. doi:10.4172/2157-7587.1000138

Page 6 of 9

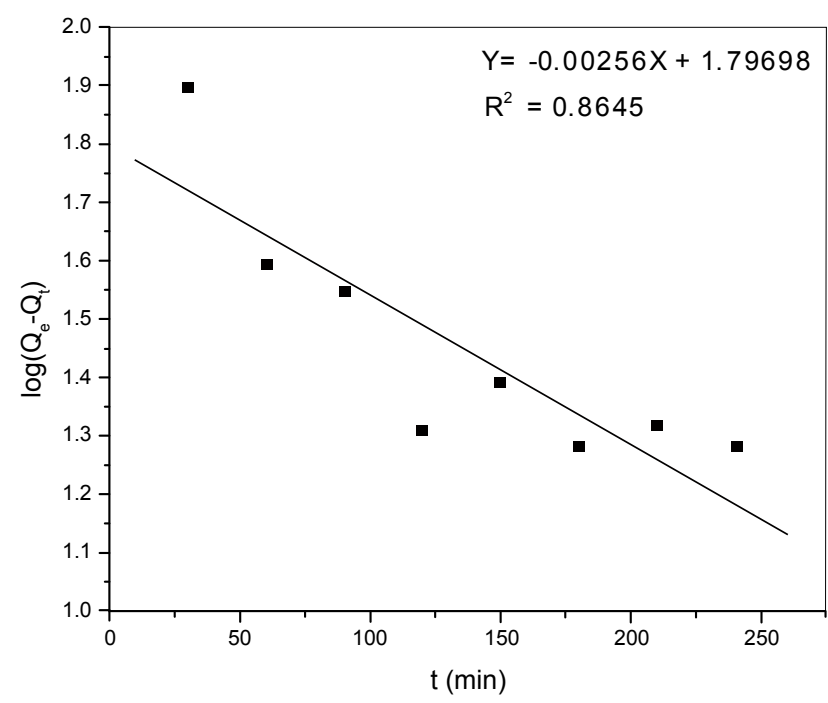

Figure 10: Linearized pseudo-first-order plot for the adsorption of crystal violet by OCMCTS.

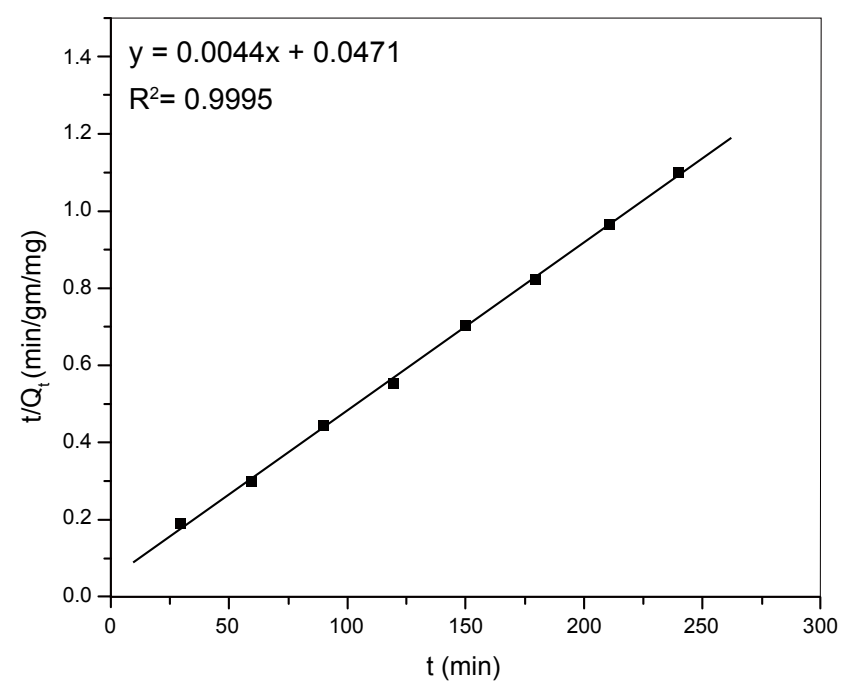

Figure 11: Linearized pseudo-second-order plot for the adsorption of crysta violet by OCMCTS.

The calculated $q_{e}$, the rate constants and the correlation coefficients for two kinetic models of OCMCTS are shown in Table 1 . The values of correlation coefficient $\left(\mathrm{R}^{2}\right)$ of pseudo-first-order and pseudo-secondorder models are 0.8644 and 0.9996 , respectively. The calculated $q_{e}$ value of the pseudo-second-order model is $244.5 \mathrm{mg} / \mathrm{g}$, which is close to the experimental data $(239.54 \mathrm{mg} / \mathrm{g})$. The higher value of correlation coefficient (0.9996) and the close calculated $q_{e}$ value indicate that these data are well fit for pseudo-second order model. On the other hand, the theoretical $q_{e}$ value $(62.65 \mathrm{mg} / \mathrm{g})$ obtained from the pseudo-firstorder model is significantly different from the experimental data and the correlation coefficient was also found to be lower than that of pseudo-second-order model. These results indicate that the adsorption of CV on cross-linked OCMCTS is not following the pseudo-firstorder kinetic. Thus, it is suggested that the adsorption of CV obeys the pseudo-second-order kinetics.

\begin{tabular}{|l|l|l|l|l|l|l|}
\hline \multirow{2}{*}{$\begin{array}{l}\text { Experimental q } \\
\left(\mathrm{mg} \mathrm{g}^{-1}\right)\end{array}$} & \multicolumn{3}{|l|}{ Pseudo-first-order constants } & \multicolumn{3}{l|}{ Pseudo-second-order constants } \\
\cline { 2 - 7 } & $\begin{array}{l}\text { qe }(\mathrm{mg} \\
\left.\mathrm{g}^{-1}\right)\end{array}$ & $\begin{array}{l}\mathrm{k}_{1}\left(\mathrm{x} 10^{-5}\right. \\
\left.\mathrm{min}^{-1}\right)\end{array}$ & $\mathrm{R}^{2}$ & $\begin{array}{l}\mathrm{qe}(\mathrm{mg} \\
\left.\mathrm{g}^{-1}\right)\end{array}$ & $\begin{array}{l}\mathrm{k}_{2}\left(\mathrm{x} 10^{-4} \mathrm{~g}\right. \\
\left.\mathrm{mg}^{-1} \mathrm{~min}^{-1}\right)\end{array}$ & $\mathrm{R}^{2}$ \\
\hline 239.54 & 62.65 & 5.89 & 0.8645 & 244.5 & 5.51 & 0.9996 \\
\hline
\end{tabular}

Table 1: Theoretically determined constants of the pseudo-first and the pseudosecond-order reaction kinetics based on the sorption of crystal violet from $25 \mathrm{mgL}^{-1}$ solutions. $\mathrm{pH} 8.0$, by $0.05 \mathrm{~g}$ cross-linked OCMCTS during shake flask sorbentsorbate contact at $30^{\circ} \mathrm{C}$ for $240 \mathrm{~min}$.

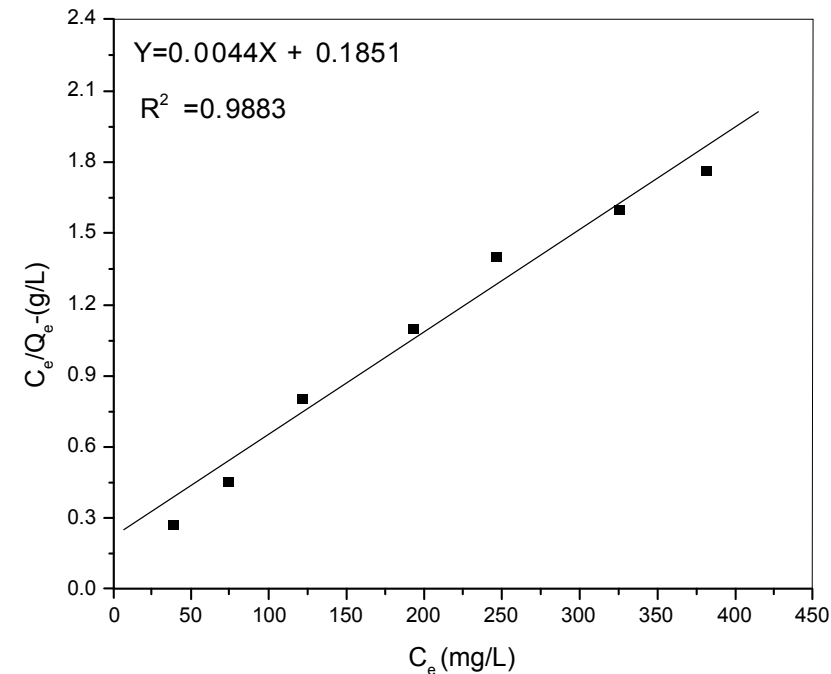

Figure 12: The linearized Langmuir adsorption isotherms for the adsorption of crystal violet by OCMCTS.

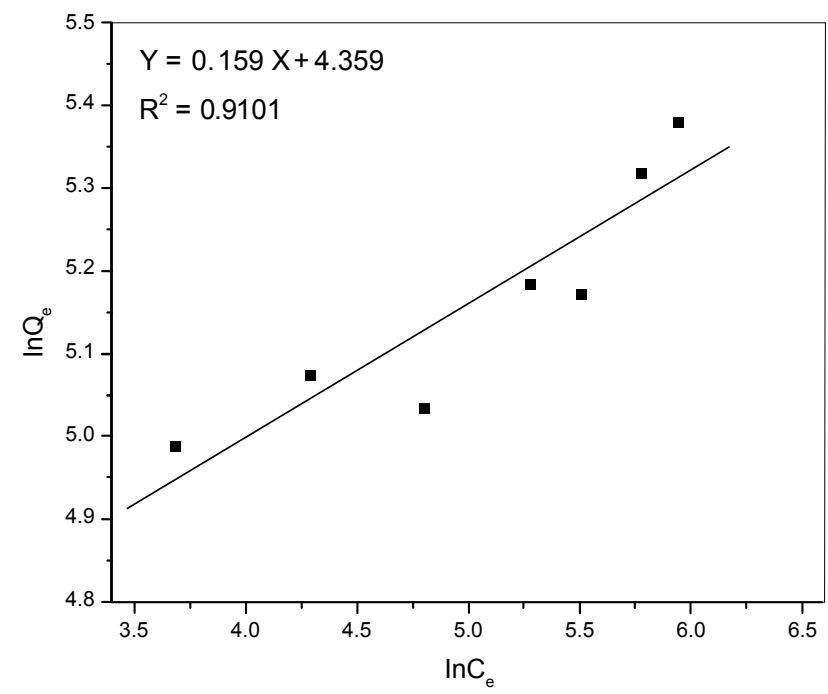

Figure 13: The linearized Freundlich adsorption isotherms for the adsorption of crystal violet by OCMCTS.

\section{Adsorption isotherms modeling}

Adsorption isotherms are important for the description of how molecules of adsorbate interact with adsorbent surface. Hence, the correlation of equilibrium data using either a theoretical or empirical equation is essential for the adsorption interpretation and prediction of the extent of adsorption. The obtained adsorption data are interpreted by the two well known isotherm equations namely, the Langmuir and the Freundlich isotherm equations [45]. 
The Langmuir isotherm equation can be represented as:

$$
\frac{C_{e}}{q_{e}}=\frac{1}{q_{\max } b}+\frac{C_{e}}{q_{\max }}
$$

where, $b$ is constant of the adsorption equilibrium $(\mathrm{L} / \mathrm{mg})$ and $q_{\max }$ is the maximum dye adsorption capacity $(\mathrm{mg} / \mathrm{g})$. The values of $q_{\max }$ and $b$ can be obtained from linear plot of $C e / q e$ versus $C e$.

The Freundlich isotherm equation based on adsorption on a heterogeneous surface is given as follows:

$$
q_{e}=K_{F} \times C_{e}^{1 / n}
$$

This equation can be rewritten as below for its linearized form:

$$
\ln q_{e}=\ln K_{F}+\frac{1}{n} \ln C_{e}
$$

Where, $\mathrm{K}_{\mathrm{F}}$ and $n$ are the Freundlich constants, which represent adsorption capacity and adsorption intensity, respectively. $\mathrm{K}_{\mathrm{F}}$ and $n$ can be obtained from intercept and slope of a linear plot of $\ln _{e}$ against $\ln \mathrm{C}_{\mathrm{e}}$.

A linear plot of $C / q_{e}$ versus $C$ for the Langmuir model of adsorption of CV on cross-linked OCMCTS is shown in Figure 12. Figure 13 shows the linear plot of Freundlich isotherm model for the adsorption of CV on cross-linked OCMCTS. The calculated values of various parameters of Langmuir and Freundlich equation are reported in Table 2. The comparison of correlation coefficients $\left(\mathrm{R}^{2}\right)$ of the linearized form of both the Langmuir and Freundlich adsorption equations indicates that the Langmuir model yields a better fit for the experimental equilibrium adsorption data than the Freundlich model. This result suggests the monolayer coverage of the dye on the surface of the OCMCTS. Similar results are also observed in previous studies like, the adsorption of methylene blue onto quaternary ammonium compounds modified monmorillonite [46], clay [47] and chitosan-gpoly (acrylic acid)/montmorillonite [48]. The maximum adsorption of CV on cross-linked OCMCTS is found to be $230.41 \mathrm{mg} / \mathrm{g}$ (from the plot), which is close to the experimental data $227.27 \mathrm{mg} / \mathrm{g}$ (Table 2). This adsorption capacity of cross-linked OCMCTS for CV is found to be quite higher than previous reported adsorbents, such as $85.47 \mathrm{mg} / \mathrm{g}$ by skin almond waste [49], $64.87 \mathrm{mg} / \mathrm{g}$ by activated rice husk [38] and $113 \mathrm{mg} / \mathrm{g}$ by activated sludge [50]

The affinity between the adsorbate and adsorbent can be obtained from the Langmuir parameter with the help of the dimensionless separation factor $\left(\mathrm{R}_{\mathrm{L}}\right)$, which can be presented as below [51]:

$$
R_{L}=\frac{1}{1+b C_{i}}
$$

In accordance with criteria of $R_{L}$ (Table 3), $R_{L}$ can be used to predict whether an adsorption system is "favorable" or "unfavorable". The $\mathrm{R}_{\mathrm{L}}$ value for this adsorption system is 0.18 (Table 2), which is lower than 1 and higher than zero. This suggests that the adsorption of CV onto OCMCTS is "favorable".

\section{Proposed adsorption mechanism}

Figure 14 represents the FT-IR spectra of cross-linked OCMCTS before and after adsorption of CV dye. Figure 14b shows that there

\begin{tabular}{|c|c|c|c|c|c|c|c|}
\hline \multirow{2}{*}{$\begin{array}{c}\text { Experimental q } \\
\left(\mathrm{mg} \mathrm{g}^{-1}\right)\end{array}$} & $\begin{array}{c}\text { qmax } \\
\left(\mathrm{mg} \mathrm{g}^{-1}\right)\end{array}$ & $\begin{array}{c}\mathrm{b}(\mathrm{L} \\
\left.\mathrm{mg}^{-1}\right)\end{array}$ & $\mathrm{R}_{\mathrm{L}}$ & $\mathrm{R}^{2}$ & $\begin{array}{c}\mathrm{KF}\left[\left(\mathrm{mg} \mathrm{g}^{-1 /}\right.\right. \\
\left.\left(\mathrm{mg} \mathrm{L}^{-1}\right)^{1 / n}\right]\end{array}$ & $1 / \mathrm{n}$ & $\mathrm{R}^{2}$ \\
\hline 239.54 & 227.27 & 0.023 & 0.18 & 0.9883 & 78.16 & 0.159 & 0.9101 \\
\hline
\end{tabular}

Table 2: The Langmuir and Freundlich isothermsmodel constants, and their respective correlation coefficients $\mathrm{R}^{2}$ for the sorption of crystal violet from aqueous solution by OCMCTS.

\begin{tabular}{|l|l|}
\hline Separation factor $\left(R_{L}\right)$ & Types of isotherms \\
\hline$R_{L}>1$ & Unfavorable \\
\hline$R_{L}=1$ & Linear \\
\hline $0>R_{L}<1$ & Favorable \\
\hline$R_{L}=0$ & Irreversible \\
\hline
\end{tabular}

Table 3: Characteristics of the Langmuir adsorption isotherms.

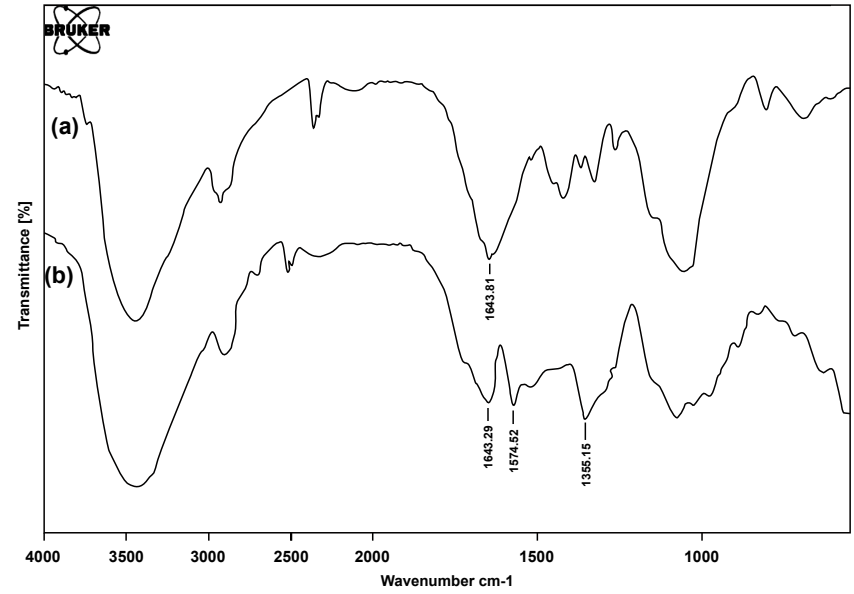

Figure 14: FT-IR spectrum of OCMCTS: before adsorption (a) and after adsorption (b).

was no significant change in the absorption intensity at wave numbers $3443.31 \mathrm{~cm}^{-1}\left(-\mathrm{OH}\right.$ stretching vibration) and $1643.81 \mathrm{~cm}^{-1}$ (superimposed of asymmetric vibration of carboxylate ion and $\mathrm{C}=\mathrm{N}$ bond). Two new absorption peaks appeared at $1574.52 \mathrm{~cm}^{-1}$ and at $1355.15 \mathrm{~cm}^{-1}$ after adsorption due to adsorption of CV dye molecule onto cross-linked OCMCTS. This implies that the adsorption processes are physical adsorption and may not involve a chemical interaction. The proposed mechanism of CV adsorption on OCMCTS is shown in Figure 15.

\section{Desorption}

For economic viability of adsorbent for water purification, it is necessary to re-generate the spent adsorbent. Figure 16 illustrates the desorption of CV from cross-linked OCMCTS at different time intervals. For desorption, the reaction responsible may be as follows:

$$
\mathrm{R}-\mathrm{COO}^{-} \mathrm{CV}-\mathrm{NMe}_{2}{ }^{+}+\mathrm{HCl} \rightarrow \mathrm{R}-\mathrm{COOH}+\mathrm{CV}-\mathrm{NMe}_{2} \mathrm{Cl}
$$

In order to study the regeneration of the cross-linked OCMCTS, three cycles of adsorption/desorption were carried out. Percentage of desorption of CV from cross-linked OCMCTS are shown in Figure 16. It is found from Figure 16 that desorption process was reasonably fast and the equilibrium was almost reached within 60 minutes. It may be observed that the percentage of desorption was quite high and the desorption percent slightly decreased with increasing the cycle number. This result is in accordance with the previous report [52].

\section{Conclusion}

The FT-IR and XRD characterization show that O-carboxymethyl chitosan and cross-linked OCMCTS are successfully synthesized. From this study, it is observed that the adsorption capacity of cross-linked OCMCTS increases largely that of CTS. The results also show that the adsorption process of $\mathrm{CV}$ on cross-linked OCMCTS is depended on $\mathrm{pH}$, temperature, initial dye concentration, degree of substitution of 


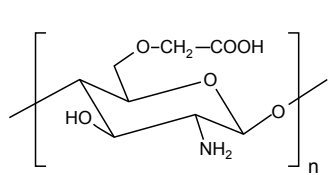

CMCTS<smiles>CN(C)c1cccc(C(=C2C=CC(=[N+](C)C)C=C2)c2cccc(N(C)C)c2)c1</smiles><smiles>CN(C)c1cccc(C(=C2C=CC(=[N+](C)C)C=C2)c2cccc(N(C)C)c2)c1</smiles>

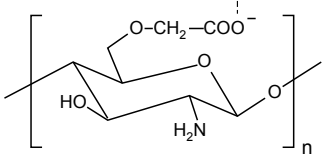

Figure 15: The proposed mechanism of CV adsorption onto OCMCTS.

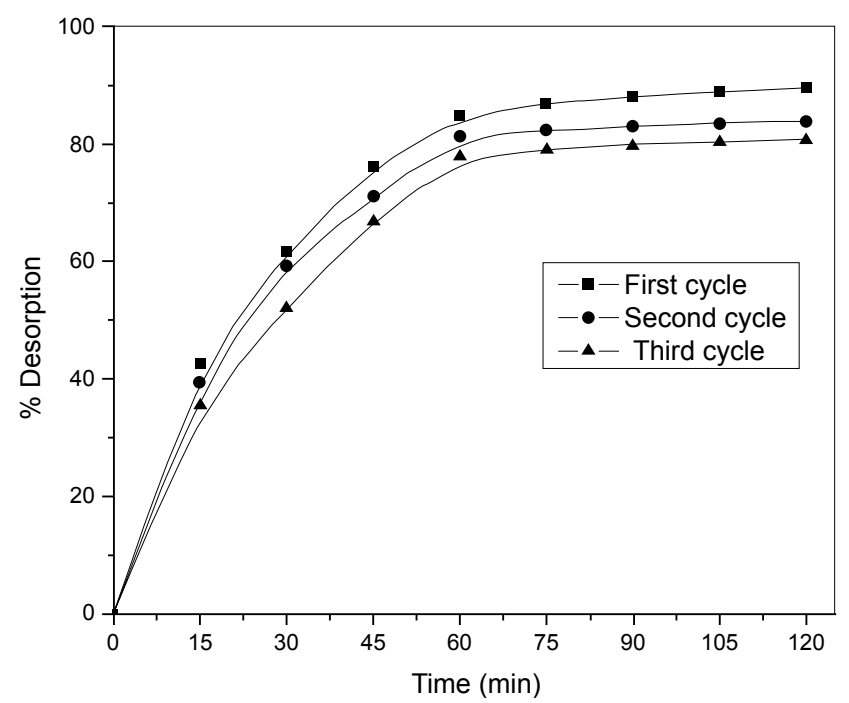

Figure 16: Desorption study of adsorbed cross-linked OCMCTS in $0.2 \mathrm{M} \mathrm{HCl}$ solution at different time interval.

OCMCTS and contact time. The adsorption process follows a secondorder-kinetic model, rather than the first-order-kinetic model. At optimized conditions, the experimental equilibrium adsorption data obtained from batch studies fits well to the Langmuir adsorption isotherm equation, rather than the Freundlich equation, indicating the formation of monolayer of CV on OCMCTS during adsorption. The dimensionless parameter $\mathrm{R}_{\mathrm{L}}$ is calculated from the Langmuir constant $b$ and the value of $\mathrm{R}_{\mathrm{L}}$ is found to be between 0 and 1 , which again suggest favorable adsorption of CV on OCMCTS. The FT-IR analysis also indicates that the adsorption of CV onto cross-linked OCMCTS is physical interaction rather than chemical interaction. From desorption study, it is found that cross-linked OCMCTS can be re-used repeatedly with slight loss of the adsorption capacity of OCMCTS. Therefore, it may be concluded that cross-linked recyclable OCMCTS can find an application as a low-cost effective adsorbent and it can be an alternative to high-cost commercial activated carbon for the removal of basic dyes from water and wastewater.

\section{References}

1. Clarke EA, Anliker R (1980) Organic dyes and pigments: The Handbook of Environmental Chemistry. Hutzinger. Springer-Verlag, Heidelberg.

2. Ali M, Sreekrishnan TR (2001) Aquatic toxicity from pulp and paper mil effluents: a review. Adv Environ Res 5: 175-196.

3. Thompson G, Swain J, Kay M, Forster CF (2001) The treatment of pulp and paper mill effluent: a review. Bioresour Technol 77: 275-286.

4. Robinson T, McMullan G, Marchant R, Nigam P (2001) Remediation of dyes in textile effluent: a critical review on current treatment technologies with a proposed alternative. Bioresour Technol 77: 247-255.

5. Saratale RG, Saratale GD, Chang JS, Govindwar SP (2011) Bacteria decolorization and degradation of azo dyes: A review. J Taiwan Institute Chem Eng 42: 138-157.

6. Auta M, Hameed BH (2011) Preparation of waste tea activated carbon using potassium acetate as an activating agent for adsorption of Acid Blue 25 dye. Chem Eng J 171: 502-509.

7. Moghaddam SS, Moghaddam MR, Arami M (2010) Coagulation/flocculation process for dye removal using sludge from water treatment plant: Optimization through response surface methodology. J Hazard Mater 175: 651-657.

8. Jirankova H, Mrazek J, Dolecek P, Cakl J (2010) Organic dye removal by combined adsorption-membrane separation process. Desalin Water Treat 20 96-101.

9. T.R.Sundararaman, V. Ramamurthi, N.Partha (2009) Decolorization and COD Removal of Reactive Yellow 16 by Fenton Oxidation and Comparison of Dye Removal with Photo Fenton and Sono Fenton Process. Modern Appl Sci 3 15-22.

10. Eyvaz M, Kirlaroglu M, Aktas TS, Yuksel E (2009) The effects of alternating current electrocoagulation on dye removal from aqueous solutions. Chem Eng J 153: 16-22.

11. Li WH, Yue QY, Gao BY, Ma ZH, Li YJ, Zhao HX (2011) Preparation and utilization of sludge-based activated carbon for the adsorption of dyes from aqueous solutions. Chem Eng J 171: 320-327.

12. Crini G (2006) Non-conventional low-cost adsorbents for dye removal: A review. Bioresour Technol 97:1061-1085

13. Sakkayawong N, Thiravetyan P, Nakbanpote W (2005) Adsorption mechanism of synthetic reactive dye wastewater by chitosan. J Colloid Interface Sci 286 36-42.

14. Babel S, Kurniawan TA (2003) Low-cost adsorbents for heavy metals uptake from contaminated water: A review. J Hazard Mater 97: 219-243.

15. Chairat M, Rattanaphani S, Bremner JB, Rattanaphani V (2008) Adsorption kinetic study of lac dyeing on cotton. Dyes and Pigments 76: 435-439.

16. Lin JX, Zhan SL, Fang MH, Qian XQ, Yang H (2008) Adsorption of basic dye from aqueous solution onto fly ash. J Environ Manage 87: 193-200.

17. Ponnusami V, Vikram S, Srivastava SN (2008) Guava (Psidium guajava) leaf powder: Novel adsorbent for removal of methylene blue from aqueous solutions. J Hazard Mater 152: 276-286.

18. Amin NK (2008) Removal of reactive dye from aqueous solutions by adsorption onto activated carbons prepared from sugarcane bagasse pith. Desalination 223: 152.

19. Han RP, Ding DD, Xu YF, Zou WH, Wang YH, et al. (2008) Use of rice husk for the adsorption of congo red from aqueous solution in column mode. Bioresour Technol 99: 2938-2946.

20. Sureshkumar MV, Namasivayam C (2008) Adsorption behavior of Direct Red $12 B$ and Rhodamine $B$ from water onto surfactant-modified coconut coir pith Colloid Surf A Physicochem Eng Aspects 317: 277-283.

21. Cheung WH, Szeto YS, McKay G (2007) Intraparticle diffusion processes during acid dye adsorption onto chitosan. Bioresour Technol 98: 2897-2904. 
Citation: Sarkar K, Debnath M, Kundu PP (2012) Recyclable Crosslinked O-Carboxymethyl Chitosan for Removal of Cationic Dye from Aqueous Solutions. Hydrol Current Res 3:138. doi:10.4172/2157-7587.1000138

22. Chang MY, Juang RS (2004) Adsorption of tannic acid, humic acid, and dyes from water using the composite of chitosan and activated clay. J Colloid Interface Sci 278: 18-25.

23. Synowiecki J, Al-Khateeb NA (2003) Production, properties, and some new applications of chitin and its derivatives. Crit Rev Food Sci Nutr 43: 145-171.

24. Vieira RS, Beppu MM (2006) Interaction of natural and crosslinked chitosan membranes with $\mathrm{Hg}(\mathrm{II})$ ions. Colloid Surf A Physicochem Eng Aspects 279: 196-207.

25. Salam MA, Makki MSI, Abdelaal MYA (2011) Preparation and characterization of multi-walled carbon nanotubes/chitosan nanocomposite and its application for the removal of heavy metals from aqueous solution. J Alloy Comp 509: 2582-2587.

26. Crini G (2006) Non-conventional low-cost adsorbents for dye removal A review. Bioresour Technol 97: 1061-1085.

27. Sherbiny IME (2009) Synthesis, characterization and metal uptake capacity of a new carboxymethyl chitosan derivative. Eur Polym J 45: 199-210.

28. Sridhari TR, Dutta PK (2000) Synthesis and characterization of maleilated chitosan for dye houseeffluent. Indian J Chem Technol 7: 198-201.

29. Choong J, Wolfgang HH (2003) Chemical modification of chitosan and equilibrium study for mercury ion removal. Water Res 37: 4770-4780.

30. Wang S, Xu X, Yang J, Gao J (2011) Effect of the carboxymethyl chitosan on removal of nickel and vanadium from crude oil in the presence of microwave irradiation. Fuel Process Tech 92: 486-492.

31. Chen XG, Park HJ (2003) Chemical characteristics of O-carboxymethyl chitosans related to the preparation conditions. Carbohydr Polym 53: 355-359.

32. Ge HC, Luo DK (2005) Preparation of carboxymethyl chitosan in aqueous solution under microwave irradiation. Carbohydr Res 340: 1351-1356.

33. Brugnerotto J, Lizardi J, Goycoolea FM, Arguelles-Monal W, Desbrieres $\mathrm{J}$, et al. (2001) An infrared investigation in relation with chitin and chitosan characterization. Polymer 42: 3569-3580.

34. Liu XF, Guan YL, Yang DZ, Li Z, Yao KD (2001) Antibacterial action of chitosan and carboxymethylated chitosan. J Appl Polym Sci 79: 1324-1335.

35. Guo BL, Yuan JF, Gao QY (2008) pH and ionic sensitive chitosan/carboxymethy chitosan IPN complex films for the controlled release of coenzyme A. Collid Polym Sci 286: 175-181.

36. Ramakrishnan M, Nagarajan S (2009) Utilization of waste biomass for the removal of basic dye from water. World Appl Sci J 5: 114-121.

37. Monash P, Pugazhenthi G (2009) Adsorption of crystal violet dye from aqueous solution using mesoporous materials synthesized at room temperature. Adsorption 15: 390-405.
38. Bhattacharyya KG, Sarma A (2003) Adsorption characteristics of the dye, brilliant green, on neem leaf powder. Dyes Pigments 57: 211-222.

39. Sarkar K. Banerjee SL, Kundu PP (2012) Removal of Anionic Dye in Acid Solution by Self Crosslinked Insoluble Dendronized Chitosan. J Waste Water Treatment \& Analysis.

40. Mohantay K, Naidu JT, Meikap BC, Biswas MN (2006) Removal of crystal violet from wastewater by activated carbons prepared from rice husk. Ind Eng Chem Res 45: 5165-5171.

41. Senthilkumaar S, Kalaamani P, Subburaam CV (2006) Liquid phase adsorption of crystal violet onto activated carbons derived from male flowers of coconut tree. J Hazard Mater 136: 800-808.

42. Saeed A, Iqbal M, Zafar SI (2009) Immobilization of Trichoderma viride fo enhanced methylene blue biosorption: batch and column studies. J Hazard Mater 168: 406-415.

43. Lagergren $S$ (1898) About the theory of so-called adsorption of soluble substances. Handlingar 24: 1-39.

44. Ho YS, McKay G (1999) Pseudo-second order model for sorption processes Process Biochem 34: 451-465.

45. Periasamy K, Namasivayam C (1995) Removal of nickel (II) from aqueous solution and nickel plating industry wastewater industry using an agriculture waste: peanut hull. Waste Manage 15: 63-68.

46. Mall ID, Srivastava VC, Agarwal NK, Mishra IM (2005) Removal of congo red from aqueous solution by bagasse fly ash and activated carbon: kinetic study and equilibrium isotherm analyses. Chemosphere 61: 492-501.

47. Gürses A, Doğar C, Yalçın M, Açkyldz M, Bayrak R, et al. (2006) The adsorption kinetics of the cationic dye, methylene blue, onto clay. J Hazard Mater 131 217-228.

48. Wang L, Zhang JP, Wang AQ (2008) Removal of methylene blue from aqueous solution using chitosan-g-poly (acrylic acid)/montmorillonite superadsorbent nanocomposite. Colloid Surf A Physicochem Eng Aspects 322: 47-53.

49. Atmani F, Bensmaili A, Mezenner NY (2009) Synthetic textile effluent remova by skin almond waste. J Environ Sci Technol 2: 153-169.

50. Chu HC, Chen KM (2002) Reuse of activated sludge biomass: I. Removal of basic dyes from wastewater by biomass. Process Biochem 37: 595-600.

51. Hall KR, Eagleton LC, Acrivos A, Vermeulen T (1996) Pore and solid diffusion kinetics in fixed bed adsorption under constant-pattern conditions. Ind Eng Chem Fundam 5: 212-223.

52. Kamari A, Wan Ngah WS, Liew LK (2009) Chitosan and chemically modified chitosan beads for acid dyes sorption. J Environ Sci 21: 296-302. 